\title{
PRODUCTION COMPARISON OF MICROALLOYED PERITECTIC AND LOW CARBON STRUCTURAL FLAT AND LONG PRODUCTS*
}

Steven G. Jansto ${ }^{1}$

\begin{abstract}
Nearly one third of the globally produced structural flat and long structural products are in the 0.11 to $0.16 \%$ carbon range. By definition, numerous steelmakers globally define this approximate carbon range as peritectic in their melting grade family within their organization. The metallurgical consequence is the result of numerous global structural specifications which allow carbon to wide carbon ranges resulting in quality issues. For example, such specifications as ASTM A588 set no minimum carbon and a 0.15 to $0.19 \% \mathrm{C}$ maximum depending on the specific grade designated within the specification. This peritectic region is specifically challenging in production compared to less than $0.10 \% \mathrm{C}$ because of solidification issues and a higher propensity for slab or billet cracking during continuous casting. During hot rolling, rejects and/or deviates are increased as well. The relative steelmaking operational cost of production is compared between peritectic and non-peritectic carbon compositions for a given specification.
\end{abstract}

Keywords: Continuous casting; Peritectic; Solidification; Stress-strain. 


\section{INTRODUCTION}

Optimization of any production process leads to enhanced quality, improved efficiencies, less scrap, less deviates and overall reduced operating cost. Within the $355 \mathrm{MPa}$ and $420 \mathrm{MPa}$ structural products sector, there exists a significant tonnage of longs, flats and shapes produced within the $0.11-0.16 \% \mathrm{C}$ range at increased overall operational cost per tonne even though the specification allows for lower carbon. It is universally accepted that the lower carbon grades are less prone to surface and internal quality problems. Therefore, from an operational cost perspective, in today's very competitive market environment, there exists a huge opportunity for structural mills to improve profitability by thoroughly assessing a shift to lower carbon steels in their product mix.

A carbon shift is suggested in order to move out of this higher cost peritectic region, especially in the microalloyed lower strength high strength low alloy (HSLA) structural grades. Within this paper, peritectic is defined at the $0.11-0.16 \% \mathrm{C}$ range and is quite congruent with global mill metallurgical terminology. The high tonnage of pertectic grades exist at some mills perceive that lower operating costs per tonne are achieved when the higher $\mathrm{C}$ and higher $\mathrm{Mn}$ approach is incorporated for HSLA plate grades. However, this is not the case if one assesses the Total Activity Based Cost (TABC) of production. This shift for structural plate and long product grades can result in immediate cost reductions which are extremely imperative in today's competitive global steelmaking environment. The TABC methodology captures actual steelmaking and hot rolling raw material and operational costs, energy costs, production rates, internal deviates and scrap, slab conditioning, repair and maintenance, scarfing, rework, customer complaints and external cost of quality [1]. TABC requires a commitment to accurately measure operational cost, capture metallurgical documentation and a deep connection between the actual costs for a given family of grades based upon carbon equivalent, energy, quality and production rates. Some mills may also connect the actual transaction price for a given order which then derives the actual margin for a given order by customer [2].

\section{STRUCTURAL ASTM STEEL SPECIFICATION ALLOWABLE MAXIMUM CARBON CONTENT}

Numerous steel specifications applied for structural applications allow C maximum levels as high as $0.26 \%$. Table 1 illustrates some ASTM specifications allowing for grades produced within this peritectic region.

\begin{tabular}{|c|c|c|c|c|c|c|c|}
\hline ASTM Spec & A242 & A514 ${ }^{1}$ & A529 & $\mathrm{A}^{2} 72^{2}$ & A588 & A913 $^{3}$ & A992 \\
\hline $\begin{array}{l}\text { \% Carbon } \\
\text { Max }\end{array}$ & 0.15 & $\begin{array}{l}0.10- \\
0.21\end{array}$ & 0.27 & $\begin{array}{l}0.21- \\
0.26\end{array}$ & $\begin{array}{l}0.15- \\
0.20\end{array}$ & $\begin{array}{l}0.12- \\
0.16\end{array}$ & 0.23 \\
\hline
\end{tabular}

Peritectic grades in the range of $0.11-0.16 \% \mathrm{C}$ are quite often applied globally for structural long and plate products. There have been recent cases of some structural mill producers actually shifting back from low $\mathrm{C}$ to peritectic carbon grades. This reversal in chemistry strategy is a step backwards in that the peritectic choice results in increased TABC for steelmaking, casting and hot rolling operations. A lack of 
measurement and metallurgical understanding makes it difficult to calculate the benefits of this change to less than $0.10 \% \mathrm{C}$.

The definition of lower carbon steels in this paper is a carbon content less than $0.10 \%$. For example, the current problem is that when customers place a steel order to a specification such as ASTM A572, there are eight different grades with various maximum allowable carbon levels. Therefore, unless a $0.10 \% \mathrm{C}$ maximum is specified by the customer, the mill can produce up to the maximum carbon level, including the entire peritectic range. This choice can be made by the mill supplier in spite of the better material property performance and improved weldability achieved from lower carbon steels. Also, for even higher yield strength grades such as ASTM A913, this specification allows up to maximum $0.16 \% \mathrm{C}$ for Grade 65 and 70 . Another implication of these wide carbon ranges is the ease to import such structural steel plate and long products.

\subsection{CARBON LEVEL IMPLICATIONS AT MILL PRODUCER AND CUSTOMER}

If a steel producer proceeds with the peritectic approach under the assumption that it is more cost effective, that particular mill is not properly analyzing or understanding their total cost of production for these carbon-microalloyed steel grades. Analysis reveals that the overall cost of melting, casting and hot rolling is lower for low carbon microalloyed grades than for the peritectic microalloyed grades. [1] Most end users rely on a given specification to meet their order requirements. Consequently, as long as the specified chemical elements meet the composition range within the specification, the shipment is deemed acceptable. Herein, two potential problems exist for the end user. First, mechanical property performance can vary significantly due to major carbon level differences between heats (i.e. as much as 0.05 to $0.10 \% \mathrm{C}$ in some cases). This situation is particularly apparent when the same specification grade is produced by multiple suppliers and/or supplied by service centers. The second problem will involve possible difficulties during the fabrication and joining of varying carbon grades.

Recent communications with end users reveal they are unaware and do not measure the actual negative cost implications to their business when the peritectic grade is processed in their operation. Concurrently, the end user market trend for these ASTM grades are demanding structural components with less mechanical property variability and better overall fabrication and joining consistency. Properties such as low temperature toughness, formability, bendability, weldability, fracture toughness and fatigue performance are impaired when these higher $\mathrm{C}$ peritectic grades are applied instead of the less than $0.10 \% \mathrm{C}$ lower carbon steels. For example, from a fabricator (i.e. end user perspective), an improvement in weldability of the material translates directly into cost savings for the end user. One very important attribute of the low carbon grades is that preheating of the steel before welding is not necessary. However, in the case of a $0.15 \% \mathrm{C}$-microalloyed grade, many fabricators require a preheat step before welding, which adds labor time, higher energy consumption and welding cost.

The Graville diagram maps different regions based upon the heat affected zone (HAZ) cracking susceptibility from the welding process. Steels falling into region I on the Graville diagram can be welded without any problems and special precautions. With the lower carbon, the more robust material and lower carbon equivalent and contributes to improved material robustness. Steels belonging to region II can be welded, but conditions must be controlled with low heat input and in some cases, 
preheating is performed. In region III, the welding of steels can be carried out by tightly controlled heat input with simultaneous preheating and good experienced welding personnel. As the material chemistry changes and moves from region I to II to III, a corresponding increase in both welding cost and rejects result. Figure 1 below illustrates the improvement in weldability when shifting from a $0.15 \% \mathrm{C}$ ASTM A572 structural peritectic (medium C) grade, which is in Zone II, compared with a $0.08 \%$ C ASTM A572 grade which is in Zone $\mathrm{I}$.

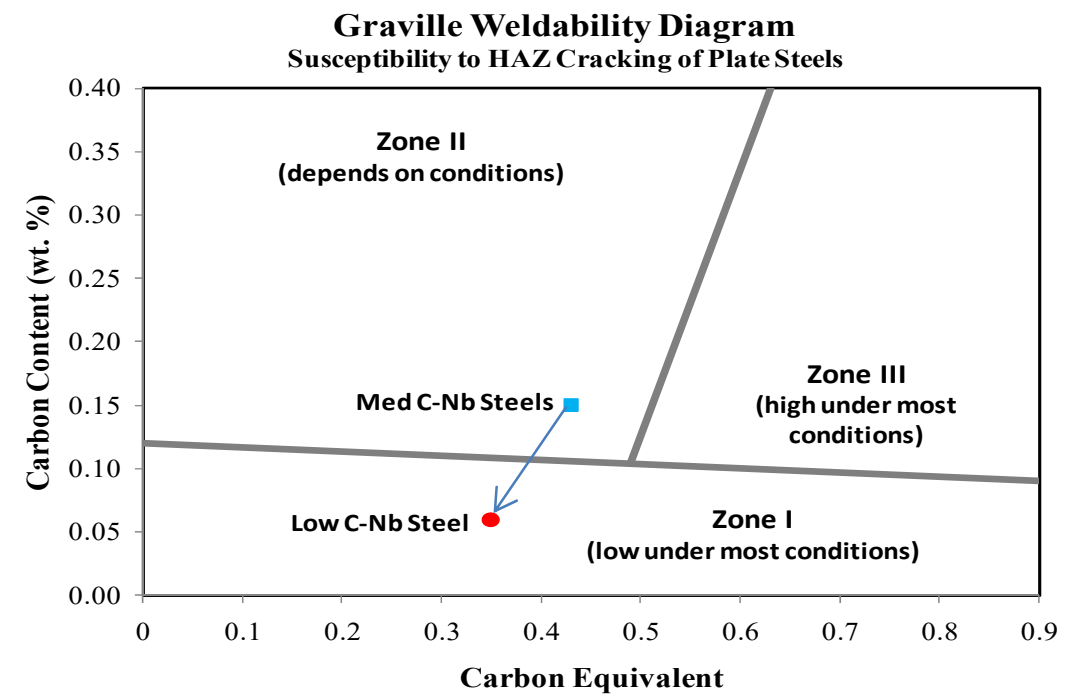

Figure 1. Graville weldability diagram

\subsection{Metallurgical Reasons for Higher Cost of Peritectic Steel Production}

The primary metallurgical reasons for higher production cost for this $0.11-0.16 \% \mathrm{C}$ (hypo-peritectic) microalloyed steel grades compared to low carbon microalloyed grades relate to negative implications at the steelmaking, casting and hot rolling steps of the process. Costs can be assigned to each item through application of the previously described TABC methodology. The list compares the low carbon to the peritectic carbon grade based upon actual operational costs. Primary differences between the low carbon and peritectic grades are listed:

1. Differences in solidification behavior during continuous casting

2. Casting requires tighter control of primary and secondary cooling for peritectic due to heat flux differences

3. Increased slab conditioning with peritectic grades due to uneven surface solidification resulting in a variable equiaxed chill zone closer to the surface compared to low carbon microalloyed grades

4. Maximum austenite grain size occurs in the $0.11-0.16 \% \mathrm{C}$ range

5. Surface quality generally worsens in hot roll product

6. Increased slab scarfing and potential to open cracks in peritectic grades

7. Often peritectic grades are normalized heat treated to homogeneous grain size, but not necessary in low carbon grades (eliminate heat treatment)

8. Grain size and mechanical property variability across the width and through the thickness

9. Peritectic grades are cast at slower speeds affecting productivity by as much as $10-20 \%$ 
10. Increase in number of transition slabs and potential downgrades

11. Peritectic grades tend to exhibit more internal and centerline segregation, especially as Mn levels increase

These increased operational costs result from fundamental metallurgical principles. Figure 2 schematically illustrates these metallurgical inter-relationships and effects on mechanical and microstructural properties [4].

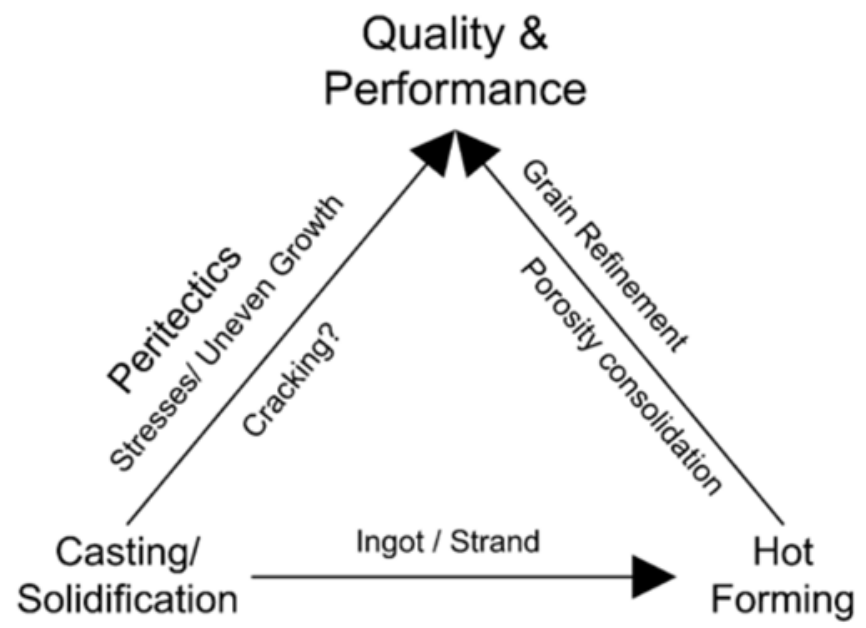

Figure 2. Peritectic steel implications

For example, since grain size and microstructure are of utmost importance in determining the strength, toughness, property variability and performance of a steel, poor cast slab quality translates directly into increased internal and external cost of quality. Specifically, within the peritectic family of grades, the hypo-peritectic steels $(0.11-0.16 \% \mathrm{C})$ impose a bottleneck for the high-speed casting in numerous operations around the world due to the strand contraction during peritectic solidification that causes non-uniform development of the shell in continuous casting mold.

Peritectic steel cost implications are of extreme importance and are incongruent with the global initiative to adopt high-speed continuous casting to improve operational performance and reduce cost. With lower carbon structural steel grades, higher casting speeds are possible. The resultant increase in productivity of steel translates into reduced operational cost per tonne, improved hot ductility during casting, and improved quality which is a priority in today's competitive global steel environment.

\subsection{Solidification Behavior of Peritectic Grades}

Carbon steels with a hypo-peritectic composition (carbon content between 0.11 and $0.16 \mathrm{wt} \%$ ), show surface crack susceptibility when they are produced by the continuous casting process, particularly at high casting speeds $[5,6]$. This susceptibility is usually attributed to a volumetric contraction previously discussed associated with the peritectic solidification phenomena, which is described by the reaction:

$$
\text { liquid }(L)+\text { primary phase }(\delta)[3] \rightarrow \text { secondary phase }(Y) \text { [7-10] }
$$


The peritectic transformation supports large austenitic grains resulting in brittle material behavior during solidification. That means, in a temperature range between Ae3 and approximately $1100^{\circ} \mathrm{C}$, the solidified shell material can easily be damaged and a crack growth along the grain boundaries can occur without any big plastic deformation. Additionally, high stresses are introduced during the early stage of solidification. A strong shrinkage takes place during the phase change from the $\delta$ ferrite to the tighter arranged $y$-austenite structure [11]. Hypo-peritectic grades often result in unstable operating conditions (mould level hunting, casting breakouts) and defective slab products (i.e. rough surface and deep oscillation marks) and surface cracks both in longitudinal and transversal direction. Although at times, it is often possible to avoid the peritectic reaction by suitable alloying additions, it is easy to push a non-peritectic steel into the peritectic range by missing the carbon aim which is dependent upon a given Basic Oxygen Furnace (BOF) or Electric Arc Furnace (EAF) carbon reduction control practices. If carbon scatter from heat-to-heat occurs, without adjustments at the hot rolling mill, the hot rolled steel can exhibit variable mechanical properties, increased yield-to-tensile ratio scatter, poor weldability and unpredictable formability behavior.

Surface quality deterioration leads to increased conditioning costs, rework and rejects. This non-uniformity in the chill zone grain size on peritectic grades result in hot spots/hot seams, and hence the occurrence of short longitudinal facial cracks. Another critical operational practice is the mold flux. Cuspidine crystallization from mould slag is one of the most effective ways of exerting heat transfer control during solidification. The result is a decrease in the heat flux from the use highly crystallizing mould fluxes. Cuspidine $\left(3 \mathrm{CaO} \cdot 2 \mathrm{SiO}_{2} \cdot \mathrm{CaF}_{2}\right)$ is one of the most important crystallized compounds in mould flux film during thin slab casting process. This crystalline layer in the slag film yields larger thermal resistance by producing an air gap at the flux/mould interface. This film is considered most promising to decrease the cracks formed during casting since it reduces both radiation- and conduction-heat transfer from the shell to mould near the meniscus and assists in forming a uniform shell [12]. However, again, increased cost is associated with the adjustments and mould flux necessary to compensate for the probable surface defects from improper temperature control during casting.

\subsection{Superheat and Liquid Steel Temperature in Tundish for Hypo-peritectic Grades}

Several process metallurgy parameters interact which often create confusing situations for operations and quality personnel when performing a root cause analysis on a quality issue. For example, most mills target to achieve a superheat of $25^{\circ} \mathrm{C}$ for these peritectic grades which equates to a tundish temperature of $1540^{\circ}$ to $1545^{\circ} \mathrm{C}$. This practice is the general worldwide standard for casting peritectic steels. However, in actual operations, it is observed that during the sequence, if the tundish temperature rises to the higher values or above $25^{\circ} \mathrm{C}$ superheat, then, at casting speeds above $1.2 \mathrm{~m} / \mathrm{min}$ there is a strong tendency for the mould level to start to fluctuate in the range of more than $+/-10 \mathrm{~mm}$. These mould level fluctuations impart surface defects which can then interact with oscillation marks. This sequence can initially form corner cracks and then transverse cracks on the cast slab surface. At times, when this surface condition is present, the transverse cracks may link together and further propagate across the slab in the straightening section of the continuous 
casting machine. As tundish temperatures increase for certain peritectic grades (even without microalloy), the slab surface defect rate increase as shown in Figure 3.

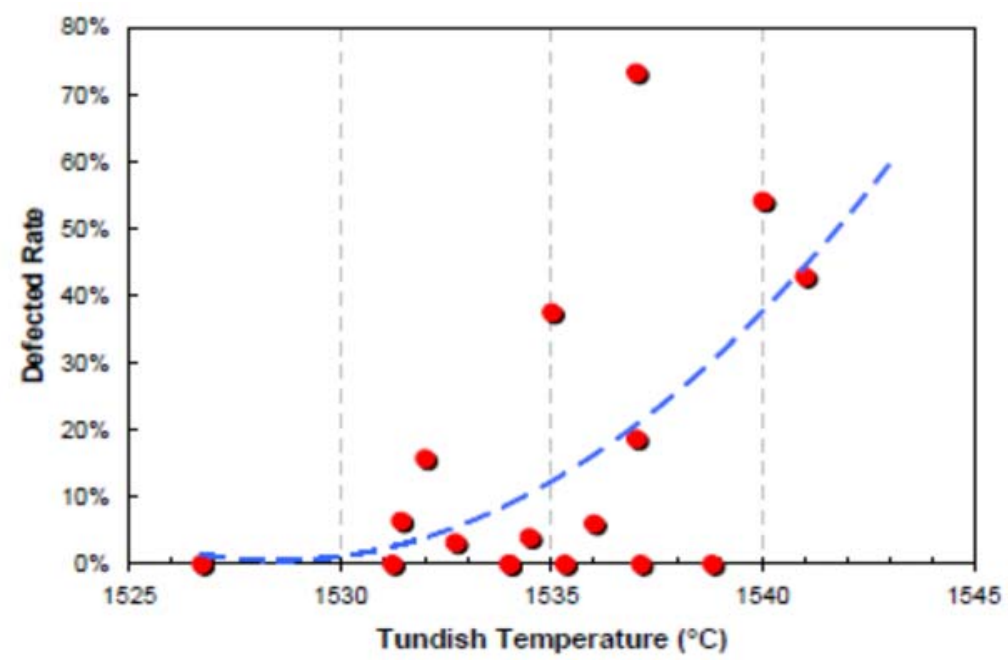

Figure 3. Tundish temperatures and slab defects [13]

World class mills actually consistently perform at $15-20^{\circ} \mathrm{C}$ superheat for automotive sheet and critical plate products. However, in the long products sector, this type of tight superheat control is quite difficult to achieve. Consequently production and quality cost increase. By shifting below $0.10 \% \mathrm{C}$, these difficulties are avoided making the operation simpler with a wider allowable superheat operational window possible resulting in more consistent quality and lower cost especially for structural and long product applications. Figure $4 \mathrm{a}$ and $4 \mathrm{~b}$ below illustrate the fundamental effect of $\mathrm{C}$ on surface cracking at different carbon levels increased austenite grain size and reduced ductility (as measured via percent reduction in area).

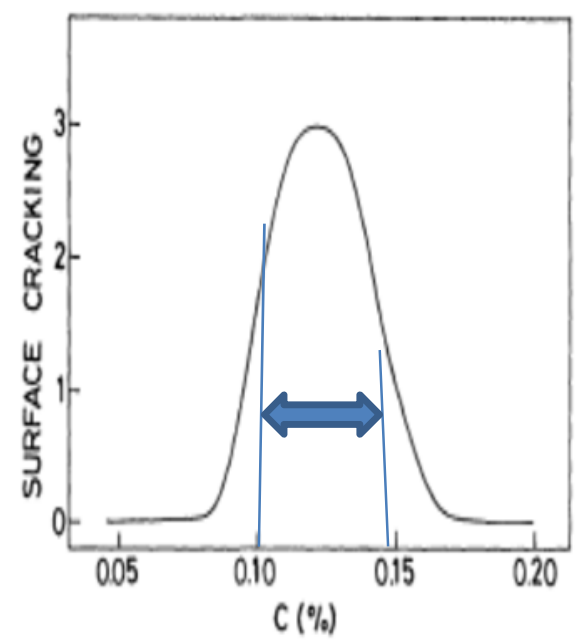

Figure 4a. Carbon content and surface cracking [14]

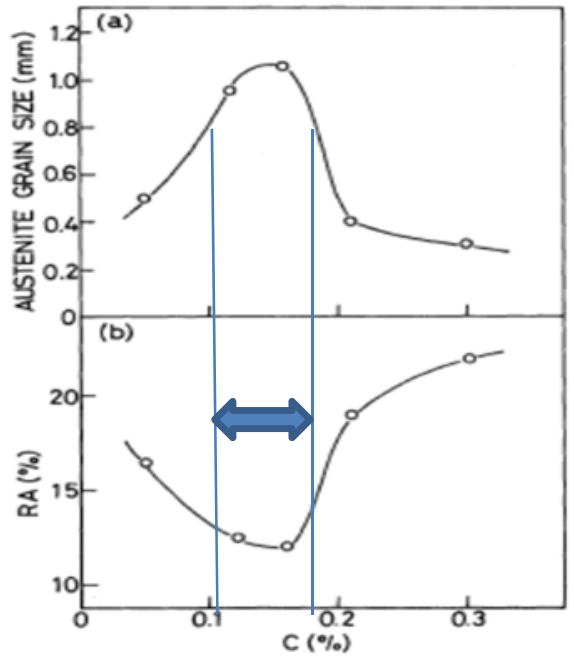

Figure 4b. Carbon content and austenite grain size and \%RA [14]

In conjunction with superheat control, especially for pertectic grades, when mould level fluctuations occur, it is necessary to reduce the casting speed to bring the fluctuation under control. One corrective action for mould level fluctuations in peritectic steels is a low liquid steel temperature in the tundish which is one of the most effective measures to avoid mould level fluctuations. Supplementary, lower 
steel superheat in the mold initiates lower stresses and strains in initial stage of strand shell solidification due to lower temperature gradient in the shell. This condition results in a lower risk of longitudinal cracking. However, operating at low tundish temperature increases the risk of nozzle problems and increased cost due to nozzle blockages during casting. The variability in surface quality is two to three times higher between the 0.11 and $0.16 \% \mathrm{C}$ range (Figure $4 \mathrm{a}$ ). This performance translates into quite variable quality for the mill and its customer, thereby increasing cost along the entire supply chain from melt shop to end user.

\subsection{Mould Heat Flux}

The inherent difference in the heat transfer rate at different carbon levels has a profound effect on solidification, especially in the less than $0.20 \% \mathrm{C}$ range. This heat transfer effect due to the carbon level affects the heat flow rates up to $0.25 \% \mathrm{C}$ and is then essentially invariant above $0.25 \% \mathrm{C}$ to $0.90 \% \mathrm{C}$ as shown below in Figure 5 .

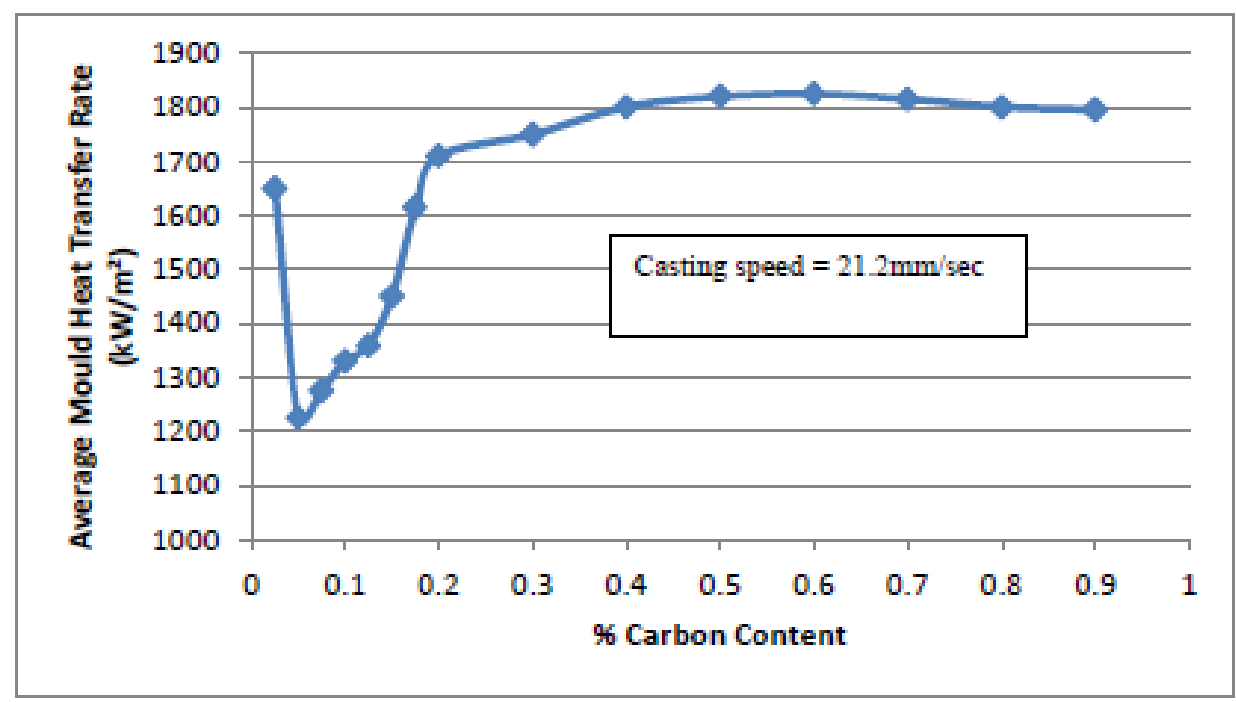

Figure 5. Average mould heat flux at different carbon contents $[15,16]$.

The mould heat flux is near a minimum between 0.05 to $0.10 \% \mathrm{C}$. The steep slope of the average heat transfer rate occurs between 0.025 and $0.050 \% \mathrm{C}$ and decreases approximately $37 \%$ from 1650 to $1210 \mathrm{~kW} / \mathrm{m}^{2}$. However, between 0.050 and $0.100 \% \mathrm{C}$ the average heat transfer rate increases only approximately $8 \%$ and is thus, easier to control with the primary cooling section in the caster compared to the 0.025 to $0.050 \% \mathrm{C}$ range. The increased shrinkage and reduced heat extraction (at the same water cooling rate) cause the formation of a rippled shell. However, as the carbon level decreases, the temperature to complete the $\delta-\gamma$ phase transformation becomes progressively lower in the mould and hence, the transformation occurs lower in the mould (where the chill zone skin is thicker lower in the mould) and the ripple formation is reduced slightly). In the carbon range of 0.100 to $0.160 \% \mathrm{C}$, the heat extraction rate increases from $1275 \mathrm{~kW} / \mathrm{m}^{2}$ to $1450 \mathrm{~kW} / \mathrm{m}^{2}$ (a $13.7 \%$ increase) and in the carbon range of 0.100 to $0.200 \% \mathrm{C}$, the heat extraction rate increases by $33 \%$. The heat extraction essentially flattens at greater than $0.400 \% \mathrm{C}$. The implications of these different mould heat flux extraction rates at different carbon ranges is huge since it directly affects the fundamental rate of solidification, equiaxed grain-chill zone depth and meniscus location in the strand. Microalloy additions in these steels do not change the heat flux appreciably, but the carbon is the primary driver. 


\section{HOT DUCTILITY BEHAVIOR GLOBAL INDUSTRIAL STUDY}

A global research study was performed on the hot ductility behavior of microalloyed steel grades and carbon levels up to $0.40 \% \mathrm{C}$ during the industrial continuous casting process. One of the objectives of this research was an evaluation of the peritectic grade behavior and operational variables affecting surface quality. Industrial samples were supplied from continuous slab caster operations in North America, China, and Europe with the associated process metallurgy conditions [17]. This study was unique as it integrates significant process metallurgy and physical metallurgy factors that interact, thereby affecting the resultant hot ductility behavior during casting on an industrial scale. There is a lack of published literature and research performed to date that directly connect the steelmaking-caster industrial operations with the resultant surface quality, hot ductility behavior, measured Percent Reduction in Area (\%RA), strain energy and surface quality performance.

This research defines the reasons for crack initiation in microalloy steel grades and more importantly, the conditions and combination of process metallurgy parameters necessary to produce crack-free slabs, sections and billets. One of the major conclusions of this research project is that $\mathrm{C}$ content is the primary element driving the hot ductility behavior and susceptibility to slab cracking. The process metallurgy parameters play a huge role in the resultant quality performance regardless of microalloy composition. The role of the microalloy has been inaccurately defined as the root cause of the surface quality issue when in fact, it is the fundamental peritectic reaction. Cracking in simple C-Mn peritectic grades is quite common under poor continuous casting process control conditions. A reduction in the carbon level was found to improve hot ductility behavior during continuous casting.

The hot ductility test results are linked to several specific caster operational parameters that influence the induced stresses during casting, as well as crack initiation and propagation during casting and straightening. The following caster machine variables were identified that directly affect surface quality, especially in peritectic grades regardless of the microalloy composition: 1) mould heat transfer, 2) mould oscillation frequencies and stroke, 3) secondary cooling flows and water distribution, 4) caster speed for various carbon equivalent grades, 5) segment alignment and 6) caster design (i.e. metallurgical length and bending radius) [17].

\section{CONCLUSION}

In conclusion, it is well accepted by producers globally that these hypo-peritectic steels are the most difficult to produce with respect to surface quality as a result of the described volume change which accompanies the ferrite to austenite transformation. The shrinkage stresses are acting in combination with thermal stresses resulting from the rather strong temperature gradient through the shell thickness for these hypo-peritectic grades. Control is much more consistent in low carbon steels $(<0.10 \% \mathrm{C})$. The primary metallurgical reasons contributing to higher production cost for $0.11-0.16 \% \mathrm{C}$ (hypo-peritectic) microalloyed steel grades are identified and compared to low carbon microalloyed grades. The analysis reveals that steel mills should meaure their own internal production and quality cost for hypoperitectic grades compared to lower carbon grades to quantify benefits at the steelmaking, casting and hot rolling steps of the process. It is recommended that producers consider a shift to lower $\mathrm{C}$ steels to improve margins for long and flat 
structural product producers minimizing the previously described metallurgical implications. The application of the Total Activity Based Cost methodology is a necessary critical success factor to capture the actual production and quality savings. Also, improved product quality for the end user will insulate the supplier to the threat currently being experienced from imports in this low margin structural steel sector.

\section{REFERENCES}

1 Jansto S. Cost effective microalloy structural steel balance of process metallurgy and materials engineering, Materials Science and Technology Conference. October 5-9. Pittsburgh, PA. 2008. 1289-1301.

2 Jansto S. Process of establishing and selling the adoption of activity-based cost. Master of Business Administration. Bowling Green State University, Bowling Green, Ohio. 1998.

3 ASTM, Standards2014, Volume 01.04, Steel-Structural, Reinforcing, Pressure Vessel and Railway, West Conshocken, PA.

$4 \quad$ Nasari $\mathrm{H}$. On peritectic reactions and transformations and hot forming of cast structures, Royal Institute of Technology (KTH), Ph.D. thesis, Stockholm, Sweden. 2009.

5 Perkins WRIA. Casting and solidification of steel. Int. Conf. Organized by the Metals Society of London and Institute of Research for the French Steelmaking (IRSID). Biarritz, France. 1977.

6 Brimacombe JK, Weinberg F and Hawbolt EB. Continuous casting, heat flow, solidification and crack formation," 2, I. S. S. of AIME. , Chelsea, U.S.A: ed. by BookCrafters; 1984.

7 Pathak SKM, Das S. and Ranganthan S. Mater. Sci. Eng. A, A323 (2002), p. 285.

8 Konishi J, Militzer M, Brimancombe JK, and Samarasekera IV. Metall. Mater. Trans. B. 2002; 33B:413.

9 Cicutti C. and Boerl R. Steel Res. Int. 2006;77:194.

10 Stefanescu DM. ISIJ Int. 2006;46:786.

11 Mondragon JR, Trejo, MH, Roman C and Solist H. Description of the hypo-peritectic steel solidification under continuous cooling and crack susceptibility. ISIJ Int. 2008;48: 454-460.

12 Gray RJ, Perkins A, and Walker B. Sheffield International Conference on Solidification and Casting, The Metals Soc. London. 1977. 967.

13 Watzinger J, Harvey A, Flick A and Y. K. Yao. High productivity slab casting of peritectic steel grades. AIST Proceedings. 2007.

14 Maehara Y, Yasumoto K, Sugitani Y and Gunji K. Effect of carbon on hot ductility of as-cast low alloy steels," Transactions ISIJ.1985; 25:1045-1053.

15 Ueda T, Hashio M, Kato H, Watanabe T and Matsui K. Tetsu-to-Hagane,1981;67:A37.

16 Saeki T, Ooguchi S, Mizoguchi S, Yamamoto T, Misumi H and Tsuneoka A. Tetsu-toHagane. 1982:68: 1773.

17 Jansto S. Hot ductility behavior in the continuous casting of niobium-bearing microalloyed steels. Ph.D. thesis, Illinois Institute of Technology, Materials Science and Engineering. Chicago, USA. December 2013. 